\title{
Removal of chromium (VI) using activated carbon-supported- functionalized carbon nanotubes
}

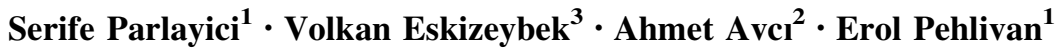

Received: 28 January 2015/ Accepted: 8 March 2015/Published online: 27 March 2015

(c) The Author(s) 2015. This article is published with open access at Springerlink.com

\begin{abstract}
The powdered activated carbon (AC) supported by carbonaceous nano-adsorbents were examined to remove hexavalent chromium $[\mathrm{Cr}(\mathrm{VI})]$ from aqueous solution The adsorption behaviour of micro-level concentration of $\mathrm{Cr}(\mathrm{VI})$ on those nano-adsorbents was investigated as a function of the experimental conditions such as the contact time, the $\mathrm{pH}$, the dosage of adsorbent, and the initial concentration of $\mathrm{Cr}(\mathrm{VI})$. The structural characterization of the adsorbents was accomplished by Fourier transform infrared spectroscopy and scanning electron microscopy. Adsorption isotherms including Freundlich and Langmuir have been applied to study the equilibrium of the adsorption behaviour and identify the adsorption capacity of the activated carbon-functionalized multiwalled carbon nanotubes (AC/f-MWCNTs) and activated carbon-functionalized carbon nanospheres (AClf-CNSs). Langmuir isotherm model showed that the adsorption process was monolayer type under working with an adsorption capacity of 113.29 and $105.48 \mathrm{mg} / \mathrm{g}$, respectively, for AC/f-MWCNTs and (AC/f-CNSs).
\end{abstract}

Keywords Adsorption - Activated carbon - Carbon nanotubes $\cdot$ Hexavalent chromium $\cdot$ Equilibrium

Erol Pehlivan

erolpehlivan@gmail.com

1 Present Address: Department of Chemical Engineering, Selcuk University, Alaaddin Keykubat Campus, 42079 Konya, Turkey

2 Department of Mechanical Engineering, Selcuk University, Alaaddin Keykubat Campus, 42079 Konya, Turkey

3 Department of Materials Science and Engineering, Canakkale Onsekiz Mart Üniversitesi, Canakkale, Turkey

\section{Introduction}

The eco-green environmental processes in chemistry are in extreme focus recently to minimize the problems associated with the contamination. Nanotechnology research has attracted extraordinary scientific attention, because nanosize materials with novel properties could efficiently be utilized in number of applications [1].

Carbon nanostructures with different morphologies, especially carbon nanotubes are assumed to be one of the major elements in nanotechnology. Multiwalled carbon nanotubes (MWCNTs) are preferred for their special physical and chemical properties. Due to their large specific surface area and uniform pore distribution, MWCNTs can be impressive candidates for potential applications of chromium removal from contaminated water reservoirs [2].

Since the US Environmental Protection Agency (EPA) declared a need for application of MWCNTs on the environmental applications in 2004, this research field was designated as one of most important areas to be investigated [3]. The superior properties of MWCNTs enable new techniques for addressing environmental applications and MWCNTs appear to be biocompatible in many environmental applications. MWCNTs are considered to be highly potential materials to improve the surface properties and structure of composite materials. The surface of carbon nanotubes has been modified intensively with chemical and physical methods to improve their dispersion property and adsorption capacities. The MWCNTs were oxidized with strong acids to introduce new functional groups on their surfaces [4-7].

Highly porous carbonaceous materials are referred to as activated carbons (ACs) that are applied in various fields owing to extraordinary characteristics [8]. The characteristics features of these materials are large surface area, 
microporous and mesoporous structures and versatile adsorption capacity for different heavy metal ions. Thereby, they can be applied as ideal adsorbents in many types of water purification systems. Because, the pore dimensions of ACs are more or less close to the size of the adsorbate molecules, they exhibit high adsorption capacity [9]. AC has become still a suitable adsorbent for wastewater treatment since the last decades.

Chromium pollution is one of the most serious environmental impacts in aqueous medium as it is nonbiodegradable. With the rapid development in novel adsorbents and their applications, adsorption technique has become a key separation process in many types of wastes from industrial applications. As a result of gathering in a large quantity, chromium can cause serious health problems. Particularly, if and when the amount of chromium becomes $0.1 \mathrm{mg} / \mathrm{g}$ of body weight, it can eventually become lethal for people. This pollutant interferes into the natural water sources from the wastewaters of leather tanning, electroplating, mining, chemical manufacturing and metal finishing industries [10]. $\mathrm{Cr}(\mathrm{VI})$ can cause cancers, mucosal ulcerations, kidney disorders and chronic dermatitis and this type of toxicity can be prevented by completing efficiently the removal of $\mathrm{Cr}(\mathrm{VI})$ from industrial wastes. Although different types of adsorbents were applied to remove chromium from wastewaters, AC and MWCNT has become still a suitable adsorbent for wastewater treatment since the last decades [11-13].

The release of $\mathrm{Cr}$ compounds from the industrial plants having a large variety of valence states should agree with the legal limits of $50 \mathrm{mg} / \mathrm{L}$ of total $\mathrm{Cr}$ concentration in drinking water [14] and $100 \mathrm{mg} / \mathrm{L}$ for discharges to surface water (US Environmental Protection Agency standards) [15]. Thus, Cr must be clarified or converted into less toxic, soluble chromium species [16]. The employment of a specific treatment technology depends on water quality, so many wastewater treatment plants carry out the process of execution for the uptake of $\mathrm{Cr}(\mathrm{VI})$. Some techniques for the removal of chromium include precipitation, filtration, ion exchange and adsorption by activated carbon, natural adsorbent and various other nanomaterials [3, 10, 17-21].

The goal of the study is to prepare advanced nano-adsorbents with enhanced efficiency to remove $\mathrm{Cr}(\mathrm{VI})$ from aqueous solution. In this study, the AC, either alone or supported with MWCNTs and ( $f$-CNSs) were applied to remove $\mathrm{Cr}(\mathrm{VI})$ and the efficiency of these nano-adsorbents were evaluated. Processing parameters including $\mathrm{pH}$, amount of AC-MWCNTs and ( $f$-CNSs), initial $\mathrm{Cr}(\mathrm{VI})$ concentration and contact time were optimized to maximize the removal of $\mathrm{Cr}(\mathrm{VI})$ from the aqueous solution.

\section{Materials and methods}

\section{Chemicals}

A 1000-ppm stock $\mathrm{Cr}(\mathrm{VI})$ solution was prepared by dissolving $2.829 \mathrm{~g} \mathrm{~K}_{2} \mathrm{Cr}_{2} \mathrm{O}_{7}$ (analytical grade) in $1 \mathrm{~L}$ distilled water. This solution was adjusted to a final concentration in the interval $0.1-1 \mathrm{mM}$ before experimental steps. The solutions of $0.1 \mathrm{M} \mathrm{HCl}$ and $0.1 \mathrm{M} \mathrm{NaOH}$ were used for $\mathrm{pH}$ adjustment during the beginning of the adsorption experiment. The powdered AC was commercially obtained from Merck while MWCNTs were purchased from Cheap Tube Inc., USA.

\section{Functionalization of MWCNTs and CNSs}

The MWCNTs were synthesized by catalytic chemical vapour deposition process, had a diameter range of $30-50 \mathrm{~nm}$, and the purity was above $95 \%$. Before use, MWCNTs were dispersed in an ultrasonic bath (Bandelin Sonopuls) in $95 \%$ ethanol solution for $1 \mathrm{~h}$ at ambient temperature to resolve MWCNT agglomerates and increase surface area before functionalization of the nanoparticle. After sonication, the slurry was filtered by the filter paper with a pore size of $0.8 \mu \mathrm{m}$ and then washed with distilled water and dried at $100{ }^{\circ} \mathrm{C}$ under vacuum. Functionalization of MWCNTs was realized by the wet chemical treatment method. The details of oxidative method for the preparation were reported by Wepasnick et al. [20]. $250 \mathrm{mg}$ $\mathrm{KMnO}_{4}$ (Carlo Erba, $98 \%$ ) was dissolved in $200 \mathrm{~mL}$ of $0.5 \mathrm{M} \quad \mathrm{H}_{2} \mathrm{SO}_{4}$ solution (Merck, 95-98\%). $100 \mathrm{mg}$ MWCNT was sonicated in $0.5 \mathrm{M} \mathrm{H}_{2} \mathrm{SO}_{4}$ solution for $30 \mathrm{~min} . \mathrm{KMnO}_{4} / \mathrm{H}_{2} \mathrm{SO}_{4}$ solution was added into MWCNT/ $\mathrm{H}_{2} \mathrm{SO}_{4}$ solution dropwise and this slurry was heated up to $150{ }^{\circ} \mathrm{C}$, subsequently. The MWCNTs $/ \mathrm{KMnO}_{4}$ mixture was then refluxed for $5 \mathrm{~h}$ at $150{ }^{\circ} \mathrm{C}$. After cooling of the MWCNTs $/ \mathrm{KMnO}_{4}$ mixture to the room temperature, $10 \mathrm{ml}$ of concentrated $\mathrm{HCl}$ (Merck, $37 \%$ ) was added to the solution. The mixture was filtered with distilled water, and functionalized MWCNTs (f-MWCNTs) were dried at $100{ }^{\circ} \mathrm{C}$ under vacuum. The same experimental procedures were repeated for functionalization of CNSs.

\section{Preparing of AC/f-MWCNTs and AC/f-CNSs}

$100 \mathrm{mg}$ of AC particles was dispersed in $100 \mathrm{~mL}$ ethanol solution in a sonication bath for $10 \mathrm{~min}$ and the certain amount of $f$-MWCNTs (wt $1 \%$ ) was dispersed in $100 \mathrm{~mL}$ ethanol solution for $10 \mathrm{~min}$ in the sonication bath. The $\mathrm{AC} /$ $f$-MWCNTs mixture was slowly sonicated for further $10 \mathrm{~min}$ and then it was placed in an oven to dry at $80{ }^{\circ} \mathrm{C}$ 
for overnight. Dried AC/f-MWCNTs were replaced in a desiccator for the adsorption experiments. The same experimental steps were repeated for the production of $\mathrm{AC} /$ f-CNSs (Scheme 1).

\section{Morphology of AC/f-MWCNTs}

Figure 1a, b shows the scanning electron microscopic (SEM) images of $\mathrm{AC}$ and $\mathrm{AC} / f$-MWCNTs particles, respectively. The AC particle displays micron-sized irregular sheet like morphology as seen in Fig. 1a and the $f$ MWCNTs can be seen on AC sheets as given in Fig. 1b. A certain amount of AC/f-MWCNTs gathered together on AC sheets in homogenous distribution and the agglomeration of $f$-MWCNTs can be clearly seen in the Fig. $1 \mathrm{~b}$.

\section{Surface area and porosity measurements}

The surface area measurements for AC, AC/f-MWCNTs and AC/f-CNSs were recorded and are given in Table 1. The results of BET method revealed that the functionalized AC/f-MWCNTs-3 \% had a higher surface area or the porosity data $\left(982.0 \mathrm{~m}^{2} / \mathrm{g}\right)$ relative to the $\mathrm{AC} / f$-CNSs $\left(875.01 \mathrm{~m}^{2} / \mathrm{g}\right)$. Hence, AC/f-MWCNTs-3 $\%$ and $\mathrm{AC} / f$ CNSs-3\% were selected and others were not preferred as a primary adsorbent in the experimental studies.

\section{FTIR analysis of AC/f-MWCNTs}

The surface chemical characteristics of AC/f-MWCNTs and AC/f-CNSs were determined by Fourier Transform Infrared Spectroscopy (FTIR), (ATR Bruker Vertex 70) and the spectrum is given in Fig. 2. The peak at $3000 \mathrm{~cm}^{-1}$ is attributed to the stretching vibration of $\mathrm{O}-\mathrm{H}$ band and aliphatic, asymmetric $\mathrm{C}-\mathrm{H}$ stretching vibration of methylene group [21]. The band at $1750-1700 \mathrm{~cm}^{-1}$ represents the acidic carbonyl $\mathrm{C}=\mathrm{O}$ stretching. The peak at $1720 \mathrm{~cm}^{-1}$ is attributed to the vibration of $-\mathrm{COOH}$ band $[10,22]$. The peak at $1500 \mathrm{~cm}^{-1}$ is corresponding to $-\mathrm{C}=\mathrm{C}-$ stretch of alkenes. The peak at $1400-1350 \mathrm{~cm}^{-1}$ represented the bending vibration of hydroxyl group. The peaks around $1000-1300 \mathrm{~cm}^{-1}$ presents C-O stretching in phenols, alcohols, acids, ethers and esters. These groups participate in $\mathrm{Cr}(\mathrm{VI})$ adsorption to $\mathrm{AC} / f$-MWCNTs and AC/f-CNSs. The surface of carbon materials is, in general, rich in a variety of surface functional groups among which the $\mathrm{C}-\mathrm{O}$ type groups are predominant and they form in ethers, acids and esters $\left(1060 \mathrm{~cm}^{-1}\right)$. FTIR analysis confirmed the presence of carboxylic and phenolic surface groups on the microporous AC/f-MWCNTs and $\mathrm{AC} / f$ CNSs. There are hydroxyl groups $\left(3000 \mathrm{~cm}^{-1} ; \mathrm{O}-\mathrm{H}\right.$ stretching mode) present in the IR spectrum of the functionalized AC/f-MWCNTs (see Fig. 2).
Scheme 1 Synthesis route of the a AC/f-MWCNTs, b AC/fCNSs and the adsorption process for $\mathrm{Cr}(\mathrm{VI})$ ions (a)

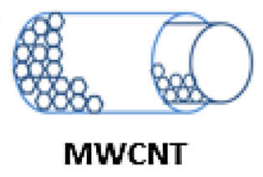

(b)

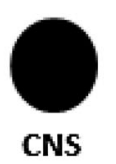

UV-Visible
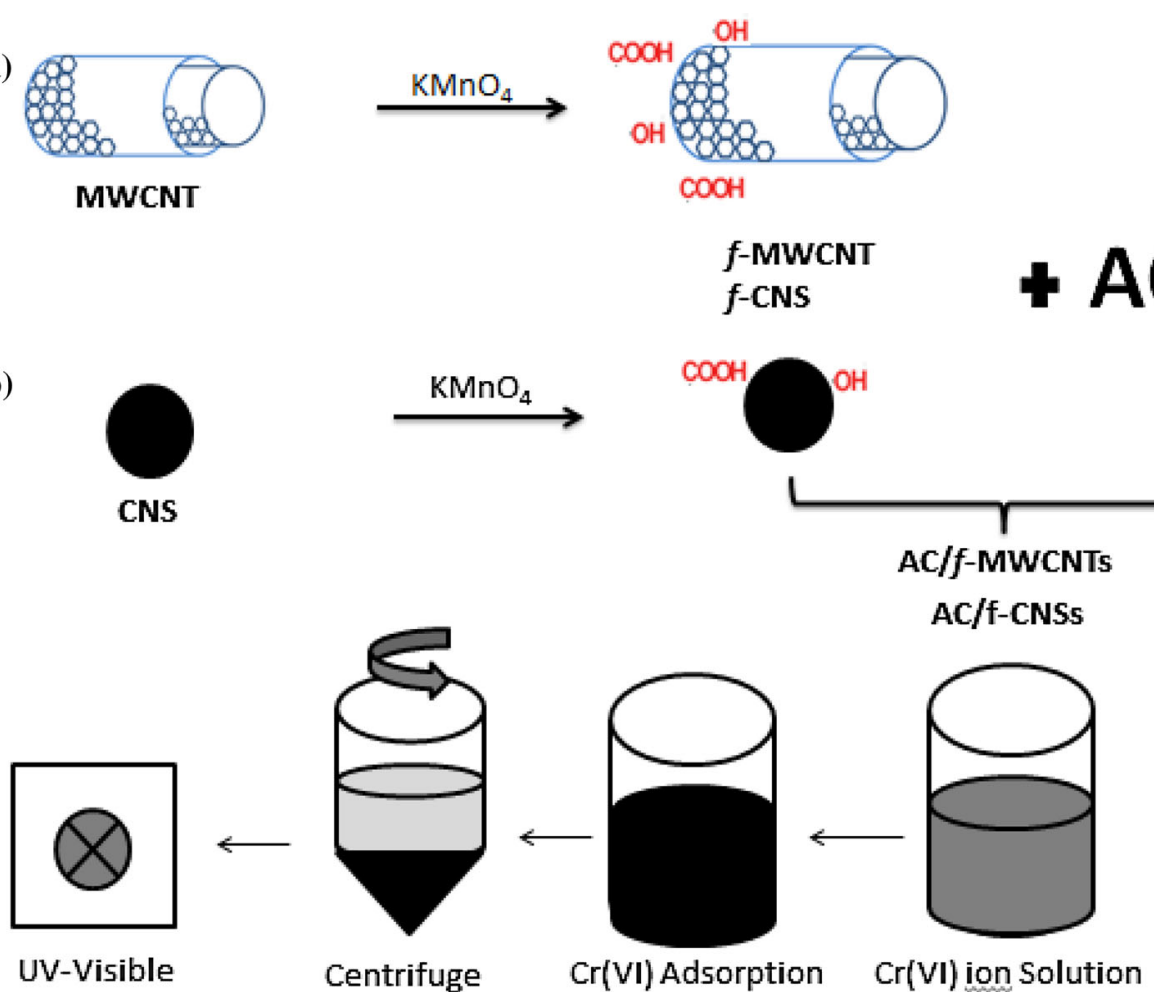

$f$-MWCNT $f$-CNS

$+A C$
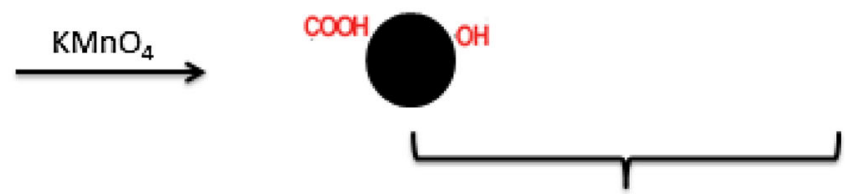

AC/f-MWCNTs AC/f-CNSs 
Fig. 1 a, b SEM images of AC and AC/f-MWCNTs- $3 \%$ before the experiment with different magnifications
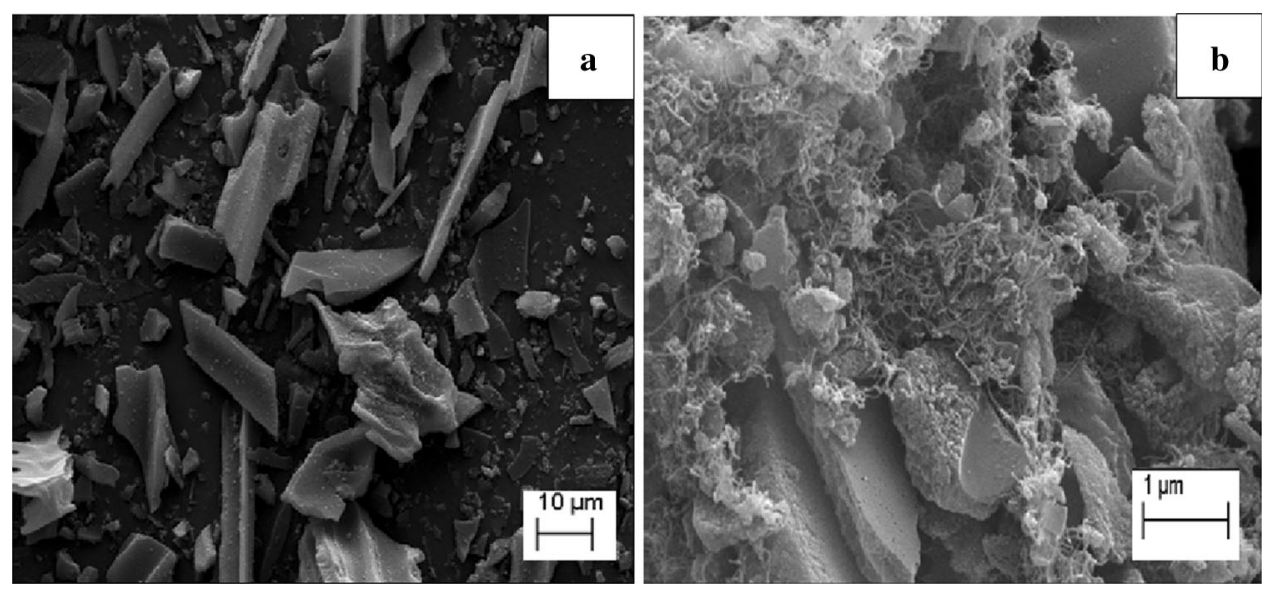

Table 1 Surface areas of for AC, AC/f-MWCNTs and AC/f-CNSs

\begin{tabular}{ll}
\hline Adsorbent & Surface area $\left(\mathrm{m}^{2} / \mathrm{g}\right)$ \\
\hline AC & 495.62 \\
AC/f-MWCNTs-1 \% & 565.26 \\
AC/f-MWCNTs-3 \% & 982.00 \\
AC/f-MWCNTs-5 \% & 373.62 \\
AC/f-CNSs-1 \% & 459.63 \\
AC/f-CNSs-3 \% & 875.01 \\
AC/f-CNSs-5 \% & 232.62 \\
\hline
\end{tabular}

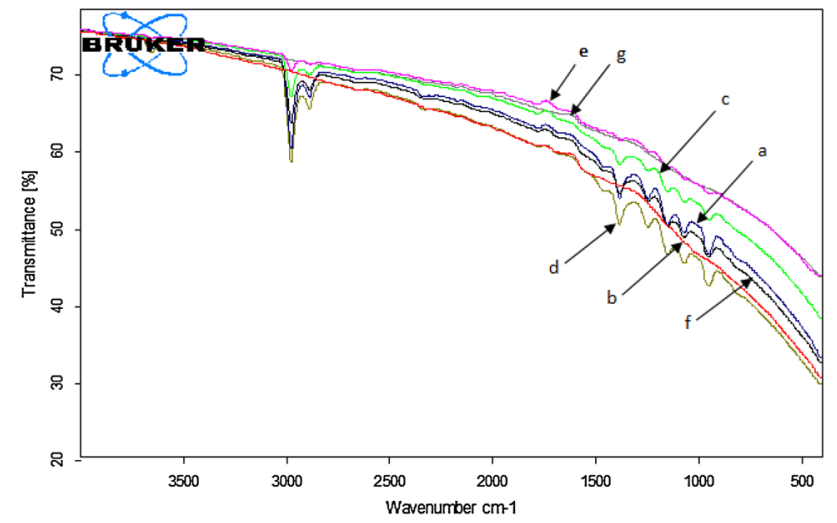

Fig. 2 FTIR analysis of adsorbents; $(a)$ AC, $(b)$ AC/f-MWCNTs$1 \%,(c)$ AC/f-MWCNTs-3 \%, (d) AC/f-MWCNTs-5 \%, (e) AC/ CNSs-1 \%, $(f)$ AC/CNSs-3 \%, $(g)$ AC/CNSs-5 \%

\section{Batch adsorption experiments}

For the batch trials, $0.2 \mathrm{~g}$ of each adsorbent was placed in contact with $50 \mathrm{~mL}$ of $1 \times 10^{-3} \mathrm{M} \mathrm{Cr}(\mathrm{VI})$ solution in the plastic-sealed beaker. The adsorbents and the $\mathrm{Cr}(\mathrm{VI})$ solution were agitated on a shaker with different contact time intervals. After each specified contact time, the $\mathrm{Cr}(\mathrm{VI})$-adsorbent suspension was filtered and the filtrates were collected for optical analysis of their $\mathrm{Cr}(\mathrm{VI})$ content with a UV-visible spectrophotometer (Shimadzu UV1700) $(\lambda 540 \mathrm{~nm})$. To investigate the influence of $\mathrm{pH}$, the adsorbents were placed in contact with the $\mathrm{Cr}(\mathrm{VI})$ solution and the $\mathrm{pH}$ was adjusted using either $0.1 \mathrm{M} \mathrm{HCl}$ or $0.1 \mathrm{M}$ $\mathrm{NaOH}$ solution. The effect of $\mathrm{pH}$ was investigated by varying this parameter from 1.5 to 7 , while the initial $\mathrm{Cr}$ (VI) concentration was fixed at $1 \times 10^{-3} \mathrm{M}$. The samples were mixed on a shaker for a contact time of $6 \mathrm{~h}$ period. The effect of the initial $\mathrm{Cr}(\mathrm{VI})$ concentrations on the adsorption was examined by preparing standard solutions of $\mathrm{Cr}(\mathrm{VI})$ in the interval $0.1-1.0 \mathrm{mM} \mathrm{Cr}(\mathrm{VI})$ solution. These solutions were left in contact with $0.2 \mathrm{~g}$ of the adsorbent for $2 \mathrm{~h}$ with agitation on a shaker until the equilibrium was reached. The samples were stirred at $\mathrm{pH} 2.2$ for a while to achieve the equilibrium. The quantity of adsorbed $\mathrm{Cr}(\mathrm{VI})$ was calculated from the following Eq. (1): Adsorption $(\%)$ of $\mathrm{Cr}(\mathrm{VI})=\left(C_{0}-C_{\mathrm{e}}\right) / C_{0} \times 100$.

\section{Results and discussion}

The application of $f$-MWCNTs for the removing of $\mathrm{Cr}(\mathrm{VI})$ from water sources is one of the pioneer studies which have been completed in environmental research areas [3, 23, 24]. This task provides high expectations on the development of wastewater treatment and environmental contamination reduction. This is due to the fact that the MWCNTs attached to the surface of the $\mathrm{AC}$; each has a small size range about $30-50 \mathrm{~nm}$ in diameter which provides much empty surface area to the adsorbents. 


\section{The effect of contact time on adsorption}

Figure 3 shows the influence of contact time on the adsorption of the AC/f-MWCNTs and AC/f-CNSs. Adsorption performed rapidly at the first $50 \mathrm{~min}$ period of the process, and then the adsorption system reached to the equilibrium. As a result, the adsorption rate proceeded with a slower rate after $60 \mathrm{~min}$. Some literature reports that AC has a weak adsorption capacity for the polluted materials $[25,26]$. The decrease in adsorption rate can be due to the filling of pores of adsorbents with water molecule. Since $\mathrm{Cr}(\mathrm{VI})$ is a highly mobile form of chromium, it can easily move through the moisture which is trapped in the adsorbent pores of the adsorbent and is therefore cannot easily be removed from the solid AC surface.

\section{The effect of initial solution pH on adsorption}

The $\mathrm{pH}$ value of the solution phase is another parameter that contributes the adsorption of $\mathrm{Cr}(\mathrm{VI})$ in the structure of AC/f-MWCNTs and AC/f-CNSs. Figure 4 shows the extent of removal of $\mathrm{Cr}(\mathrm{VI})$ versus with initial solution $\mathrm{pH}$. It is indicated that the $\mathrm{Cr}(\mathrm{VI})$ removal efficiency increases with the initial $\mathrm{pH}$ of the solution at the low $\mathrm{pH}$ values. The highest removal efficiency was achieved at $\mathrm{pH} 2.0$ in the adsorption. The adsorption process is based on the equilibrium effect due to the difference in the thermodynamic equilibrium for each adsorbate-adsorbent interaction during the shaking of mixture.

When $f$-MWCNTs and $\mathrm{AC} / f$-CNSs are present in $\mathrm{AC}$, the adsorbents gain a higher capacity or feature for $\mathrm{C}(\mathrm{VI})$. The existence of various surface functional groups, such as basic, phenolic, carboxyl, carbonyl and hydroxyl groups [27], on the surface of AC/f-MWCNTs and AC/f-CNSs increased the adsorption amount of $\mathrm{Cr}(\mathrm{VI})$. Some suggestive mechanisms for the adsorption of $\mathrm{Cr}(\mathrm{VI})$ by the $\mathrm{AC} / f$ MWCNTs and AC/f-CNSs are electrostatic attraction,

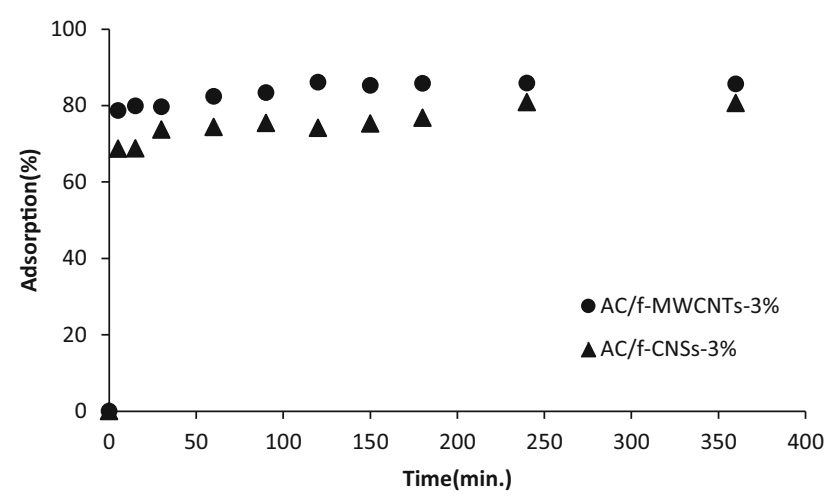

Fig. 3 Effect of contact time (resin amount: $0.02 \mathrm{~g}, \mathrm{pH}=2.2$, $T=25{ }^{\circ} \mathrm{C}$, conc. $=1 \times 10^{-3} \mathrm{M}$ )

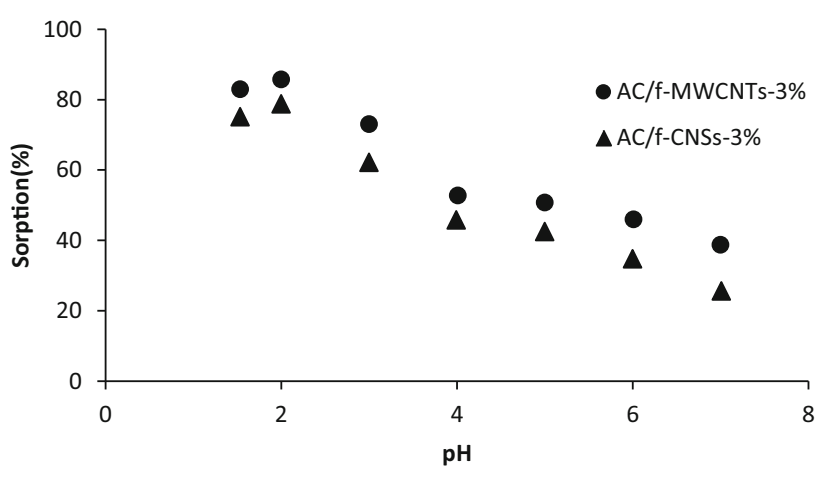

Fig. 4 Effect of $\mathrm{pH}$ (adsorbent amount $=0.05 \mathrm{~g} / \mathrm{L}, T=25^{\circ} \mathrm{C}$, conc. $\left.=1 \times 10^{-3} \mathrm{M}\right)$

complex formation, physical adsorption and chemical interaction between the chromium ions and the surface functional groups of AC/ $f$-MWCNTs. Among all of them, complex formation and electrostatic attraction between $\mathrm{Cr}(\mathrm{VI})$ ions and the surface functional groups of $\mathrm{AC} / f$ MWCNTs and AC/f-CNSs is the major adsorption mechanism.

$\mathrm{AC}$ has more basic groups on the carbon surface than MWCNTs. Therefore, by decreasing $\mathrm{pH}$ of the solution, the basic groups could adsorb chromium ions. In other words, by decreasing the negative charge density on the adsorbent surface, the electrostatic force of adsorption between $\mathrm{Cr}(\mathrm{VI})$ ions and surface increases. The chromic acid predominates at $\mathrm{pH}$ values less than about $1.0, \mathrm{HCrO}_{4}{ }^{-}$at $\mathrm{pH}$ range of $1.0-6.0, \mathrm{Cr}_{2} \mathrm{O}_{7}{ }^{2-}$ and $\mathrm{CrO}_{4}{ }^{2-}$ at $\mathrm{pH}$ values above 6.0. For $\mathrm{AC}$, more adsorption at acidic $\mathrm{pH}$ indicates that lower $\mathrm{pH}$ results in an increase in $\mathrm{H}^{+}$ions on the adsorbent surface that results in significantly strong electrostatic attraction between positively charged adsorbent surface and chromium ions. It has also been suggested that, under acidic conditions, $\mathrm{Cr}(\mathrm{VI})$ could be reduced to $\mathrm{Cr}$ (III) in the presence of AC. Most of the functional groups on MWCNTs surface are phenolic and these can be transformed into $\mathrm{C}_{x} \mathrm{O}$ at low $\mathrm{pH}$ values of the solution.

The stability of $\mathrm{Cr}(\mathrm{VI})$ which depends on the $\mathrm{pH}$ of the solution and chromium exists in different forms such as $\mathrm{HCrO}_{4}{ }^{-}, \mathrm{Cr}_{2} \mathrm{O}_{7}{ }^{2-}, \mathrm{CrO}_{4}{ }^{2-}$ in aqueous medium. At low $\mathrm{pH}$, both $\mathrm{HCrO}_{4}{ }^{-}$and $\mathrm{Cr}_{2} \mathrm{O}_{7}{ }^{2-}$ ions coexist in the solution phase. The active form of $\mathrm{Cr}(\mathrm{VI})$ adsorbed on the adsorbent is $\mathrm{HCrO}_{4}{ }^{-}$and this form is stable only at a lower $\mathrm{pH}$ range, which leads to remove of chromium efficiently. The strong pH-dependent adsorption of $\mathrm{Cr}(\mathrm{VI})$ on AC/f-MWCNTs and $\mathrm{AC} / f$-CNSs offers that the adsorption of $\mathrm{Cr}(\mathrm{VI})$ is chiefly dominated by surface complexation. It is important to indicate that the hydroxylated surface groups vary at different $\mathrm{pH}$ values because of the protonation/deprotonation processes (i.e., $\mathrm{C}_{x} \mathrm{OH}+\mathrm{H}^{+} \leftrightarrow \mathrm{C}_{x} \mathrm{OH}_{2}^{+}$at low $\mathrm{pH}$, and $\mathrm{C}_{x} \mathrm{OH} \leftrightarrow \mathrm{C}_{x} \mathrm{O}^{-}+\mathrm{H}^{+}$at high $\mathrm{pH}$ ) [21]. The negatively 
charged $\mathrm{Cr}(\mathrm{VI})$ is readily to be adsorbed to AC/f-MWCNTs and $\mathrm{AC} / f$-CNSs at low $\mathrm{pH}$ values, and difficult to be removed at high $\mathrm{pH}$ values. At high $\mathrm{pH}$ values, the higher the valence of the adsorbed anions, the more negative the surface becomes, hence inhibiting the further adsorption of $\mathrm{Cr}(\mathrm{VI})$. Two types of mechanism can be described for $\mathrm{Cr}(\mathrm{VI})$ removal: the first type removal of $\mathrm{Cr}(\mathrm{VI})$ anions directly from the solution and the second type rely on the reduction of $\mathrm{Cr}(\mathrm{VI})$ to $\mathrm{Cr}(\mathrm{III})$. In the presence of a reducing substrate $\left(\mathrm{C}_{x} \mathrm{OH}\right)$, the $\mathrm{Cr}(\mathrm{VI})$ species are readily reduced into $\mathrm{Cr}$ (III) ions as presented by the following equations where $\mathrm{C}_{x}$ is the carbon $[2,21]$.

$$
\begin{aligned}
3 \mathrm{C}_{x} \mathrm{OH}+\mathrm{Cr}_{2} \mathrm{O}_{7}^{2-}+4 \mathrm{H}^{+} \rightarrow & 3 \mathrm{C}_{x} \mathrm{O}+\mathrm{HCrO}_{4}^{-}+\mathrm{Cr}^{3+} \\
& +3 \mathrm{H}_{2} \mathrm{O}
\end{aligned}
$$

$3 \mathrm{C}_{x} \mathrm{OH}+\mathrm{HCrO}_{4}^{-}+4 \mathrm{H}^{+} \rightarrow 3 \mathrm{C}_{x} \mathrm{O}+\mathrm{Cr}^{3+}+4 \mathrm{H}_{2} \mathrm{O}$

It is clear that $\mathrm{Cr}(\mathrm{VI})$ is reduced to $\mathrm{Cr}(\mathrm{III})$ in the presence of reducing substrate $\left(\mathrm{C}_{x} \mathrm{OH}\right)$ on the occurrence of redox reactions between the surface groups and the $\mathrm{Cr}(\mathrm{VI})$ at low $\mathrm{pH}$ values. The reduction reaction can be maintained by the higher degree of adsorption that happens at lower $\mathrm{pH}$ where $\mathrm{Cr}(\mathrm{VI})$ is known to be reduced to $\mathrm{Cr}(\mathrm{III})$ [3]. This mechanism is coupled to the oxidation of the $\mathrm{AC} / f$ MWCNTs and AC/f-CNSs surface which will suitably contain carboxyl groups. The obtained $\mathrm{Cr}$ (III) ions are chemisorbed by forming bonds with the oxygen atoms on the carbonyl groups. Electrostatic interactions between the anions and the electron-rich functional groups on the $\mathrm{AC} / f$ MWCNTs and AC/f-CNSs surfaces may lead the adsorption process to be decreased. The adsorbent surface may become negative and the adsorption does not occur anymore after $\mathrm{pH}$ value greater than 4 .

The $\mathrm{pH}_{\mathrm{zpc}}$ of the adsorbent was measured as 8.0. The $\mathrm{pH}_{\mathrm{PZC}}$ of the AC/f-MWCNTs suggests that electrostatic repulsion plays a key role in case dichromate ions are larger than the hydroxyl ions and can be easily displaced from the adsorption sites. Adsorption of $\mathrm{Cr}(\mathrm{VI})$ on the adsorbents was relatively less sensitive to an increase in $\mathrm{pH}$ increment for the values higher than 6.0. This indicates that the lower number of deprotonated functional groups on the $\mathrm{AC} / f$-MWCNTs and AC/f-CNSs reduced the positive surface charge earlier, and that $\mathrm{Cr}(\mathrm{VI})$ adsorption slowed down at a lower $\mathrm{pH}_{\mathrm{pzc}}$.

Adsorption of $\mathrm{Cr}(\mathrm{VI})$ can be reduced at higher $\mathrm{pH}$ where $\mathrm{Cr}(\mathrm{VI})$ predominates as $\mathrm{Cr}_{2} \mathrm{O}_{7}{ }^{2-}$. This phenomenon basically shows that there should be a competition between the excess hydroxyl ions present at a higher $\mathrm{pH}$ and the negatively charged dichromate ions in the solution phase for the active adsorption sites on the adsorbent surfaces. The carboxylic and hydroxyl groups of AC/f-MWCNTs and $\mathrm{AC} / \mathrm{f}$-CNSs are completely protonated below $\mathrm{pH} 8.0$, and an electrostatic attraction can occur between the positively charged adsorbent molecules and chromate anion. Moreover, the hydroxyl groups on the surface of adsorbents behave as electron donor groups and reduce $\mathrm{Cr}(\mathrm{VI})$ to $\mathrm{Cr}(\mathrm{III})$. AC/f-MWCNTs and AC/f-CNSs indicate a high adsorption efficiency at low initial $\mathrm{pH}$ values, and the adsorption efficiency decreases continuously beyond $\mathrm{pH}$ 7. Note that $\mathrm{Cr}$ (III) is the thermodynamically stable form of chromium at acidic $\mathrm{pH}<3$, and the reduction of $\mathrm{Cr}(\mathrm{VI})$ to $\mathrm{Cr}(\mathrm{III})$ can occur suddenly at acidic $\mathrm{pH}$ because of a $\mathrm{pKa}$ value of 2.4. Thus, at lower values of $\mathrm{pH}, \mathrm{Cr}$ (III) polymerized to $\mathrm{Cr}$ oxides $[2,28]$. Thermodynamically, $\mathrm{pH}$ controls the stability of $\mathrm{Cr}(\mathrm{VI})$ in the solution phase and is an important factor affecting the adsorption equilibrium. Although $\mathrm{HCrO}_{4}^{-}$is the predominant species under conditions of acidic $\mathrm{pH}$, we considered that both forms of $\mathrm{HCrO}_{4}{ }^{-}$and $\mathrm{CrO}_{4}{ }^{2-}$ were the primary species when evaluating the effect of $\mathrm{pH}$ at the equilibrium to cover the main reactions at all $\mathrm{pH}$ ranges. These two species and the protonated functional groups on the surface of the adsorbents electrostatically attract each other at low $\mathrm{pH}$ values. The more positive the surface charge of AC/f-MWCNTs and $\mathrm{AC} / f$-CNSs, the faster the adsorption rate of $\mathrm{Cr}(\mathrm{VI})$ in the solution, since the binding of anionic $\mathrm{Cr}(\mathrm{VI})$ ion species is increased through the electrostatic attraction. This is in agreement with previous studies on the adsorption of other heavy metal anions [29-31].

\section{The effect of initial $\mathrm{Cr}(\mathrm{VI})$ concentration}

The initial concentration of $\mathrm{Cr}(\mathrm{VI})$ provides an important driving force to overcome all mass transfer resistances of anions between the aqueous and $\mathrm{AC} / f$-MWCNTs and $\mathrm{AC} / f$ CNSs phases. Figure 5 shows that $\mathrm{Cr}(\mathrm{VI})$ removal decreased with increasing $\mathrm{Cr}(\mathrm{VI})$ concentration. Since the concentration of adsorbent was fixed as $0.02 \mathrm{~g}$, the number of active adsorption sites remained constant and they finally became saturated with dichromate ions. Hence due to the saturation of the adsorption sites on the adsorbents, adsorption rate of $\mathrm{Cr}(\mathrm{VI})$ is reduced. To examine the relationship between $\mathrm{Cr}(\mathrm{VI})$ adsorbed $\left(q_{\mathrm{e}}\right)$ and the aqueous concentration $\left(C_{\mathrm{e}}\right)$ at equilibrium, some isotherm models are widely implied. Here Langmuir and Freundlich models are represented in Table 2 . The conventional usage of this model is:

Langmuir equation:

$q_{\mathrm{e}}=\frac{A_{\mathrm{s}} K_{\mathrm{b}} C_{\mathrm{e}}}{1+K_{\mathrm{b}} C_{\mathrm{e}}}$,

where $A_{\mathrm{s}}(\mathrm{mmol} / \mathrm{g})$ and $K_{\mathrm{b}}(\mathrm{L} / \mathrm{mol})$ are the coefficients, $q_{\mathrm{e}}$ is the $\mathrm{Cr}(\mathrm{VI})$ ion amount adsorbed per unit mass of adsorbent and $C_{\mathrm{e}}$ is the equilibrium $\mathrm{Cr}(\mathrm{VI})$ concentration in 
Fig. 5 Adsorption isotherms of $\mathrm{Cr}(\mathrm{VI})$ on a AC/fMWCNT-3 \%, b $\mathrm{AC} / \mathrm{CNSs}-3 \%$ (conditions: initial concentration of $\mathrm{Cr}(\mathrm{VI})$, 0.1-1.0 mM; amount of adsorbent, $0.02 \mathrm{~g}$; volume of adsorption medium, $50 \mathrm{~mL}$; temperature, $25 \pm 1{ }^{\circ} \mathrm{C}$; stirring rate $180 \mathrm{rpm}$; stirring time, $24 \mathrm{~h} ; \mathrm{pH}$ 2.2.)
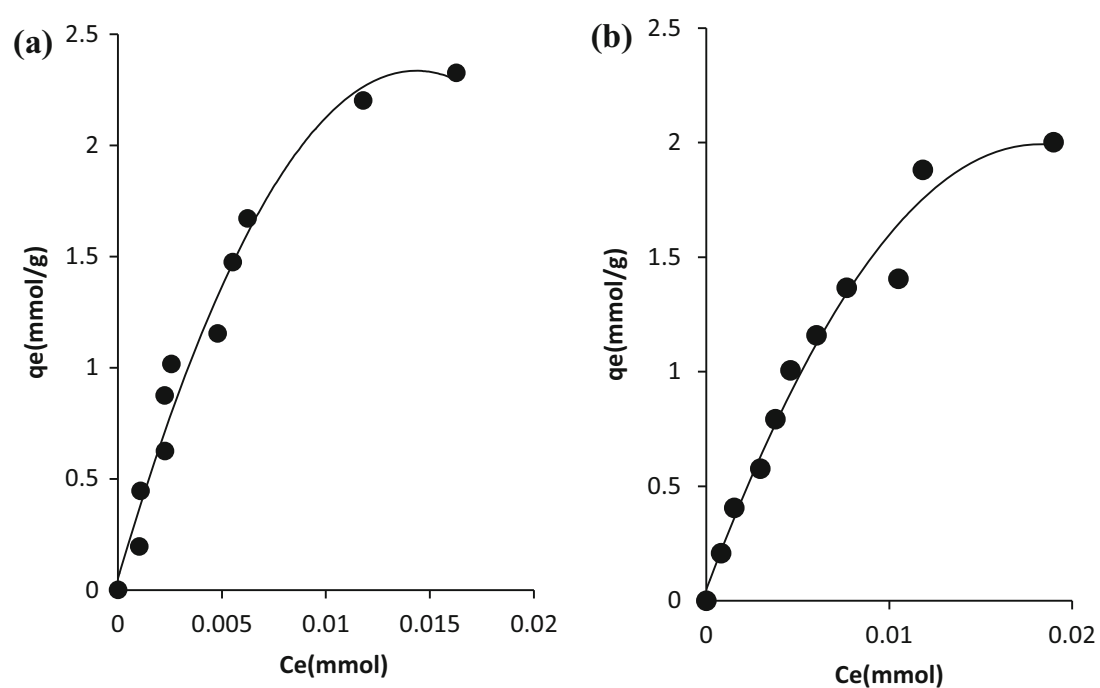

Table 2 Langmuir and Freundlich parameters of $\mathrm{Cr}(\mathrm{VI})$ adsorption

\begin{tabular}{lrlllllll}
\hline Adsorbents & \multicolumn{2}{l}{ Langmuir } & & & \multicolumn{2}{l}{ Freundlich } \\
\cline { 2 - 3 } & \multicolumn{1}{c}{$K_{\mathrm{b}}$} & $A_{\mathrm{s}}$ & $R^{2}$ & & $k$ & $n$ & $R^{2}$ \\
\hline AC & 53.58 & 5.49 & 0.8 & & 0.75 & 1.12 & 0.87 \\
AC/f-MWCNTs-1 \% & 61.49 & 4.40 & 0.85 & & 0.61 & 1.24 & 0.89 \\
AC/f-MWCNTs-3 \% & 113.29 & 3.15 & 0.99 & & 0.49 & 1.43 & 0.96 \\
AC/f-MWCNTs-5 \% & 94.81 & 3.40 & 0.87 & & 0.56 & 1.32 & 0.93 \\
AC/f-CNSs-3 \% & 105.48 & 3.27 & 0.98 & & 0.55 & 1.36 & 0.90 \\
\hline
\end{tabular}

solution phase. By rearranging Eq. (4), Eq. (5) was obtained:

$\frac{C_{\mathrm{e}}}{q_{\mathrm{e}}}=\frac{C_{\mathrm{e}}}{A_{\mathrm{s}}}+\frac{1}{A_{\mathrm{s}} K_{\mathrm{b}}}$.

The Freundlich equilibrium isotherm model describes adsorption by heterogeneous energetic distribution of adsorption sites accompanied by interaction between solute molecules (Eq. 6).

Freundlich equation:

$\left(\frac{x}{m}\right)=k C_{\mathrm{e}}^{1 / n}$,

where $n$ is the Freundlich constant and $k$ is adsorption coefficient, $x / m$ is the amount of $\mathrm{Cr}(\mathrm{VI})$ ions adsorbed per unit amount of adsorbent and $C_{\mathrm{e}}$ is $\mathrm{Cr}(\mathrm{VI})$ concentration at equilibrium in aqueous phase. By rearranging Eq. (6), Eq. (7) was obtained.

$\log \left(\frac{x}{m}\right)=\log k+\frac{1}{n} \log C_{e}$.

The Freundlich isotherm and the Langmuir isotherm apply to AC/f-MWCNTs adsorbate system. The isotherm giving an $R^{2}$ value closest to unity was deemed to provide the best fit. The Freundlich model has contained two useful parameters $(k$ and $n)$ [32, 33]. The Langmuir isotherm model has two parameters $\left(K_{\mathrm{b}}\right.$ and $\left.A_{\mathrm{s}}\right)$. It can be seen from Fig. 5 that the plots obtained for AC/f-MWCNTs are linear with $R^{2}$ values of 0.92 and 0.98 , respectively, for Freundlich and Langmuir equations. The $1 / n$ values for the functionalized AC/f-MWCNTs are calculated as 0.71 from the data and this value is less than 1 suggesting that favourable adsorption occurs. The maximum adsorption capacity for $\mathrm{Cr}(\mathrm{VI})$ using $\mathrm{AC} / f$-MWCNTs and $\mathrm{AC} / f$-CNSs were found to be 113.29 and $105.48 \mathrm{mg} / \mathrm{g}$, respectively. Langmuir isotherm satisfies the equation and monolayer adsorption on the surface of adsorbent which has a finite number of binding sites. It can be assume that the energies of adsorption are uniform and no transmigration of $\mathrm{Cr}(\mathrm{VI})$ takes place in the skeleton of the adsorbing surface.

\section{The effect of amount of adsorbent on adsorption}

The influence of different varieties of adsorbent amount on the removal of $\mathrm{Cr}(\mathrm{VI})$ ion by $\mathrm{AC} / f$-MWCNTs and $\mathrm{AC} / f$ CNSs is shown in Fig. 6. The amount of adsorbent was varied from 0.01 to $0.10 \mathrm{~g}$. The equilibrium concentration in solution phase decreases with the increasing adsorbent amount for a given initial $\mathrm{Cr}(\mathrm{VI})$ concentration and remained almost constant when adsorbent amount was above $0.1 \mathrm{~g}$. The $\mathrm{Cr}(\mathrm{VI})$ removal by AC/f-MWCNTs was calculated as $90.5 \%$.

\section{Effect of ions on adsorption}

The competing anions of chloride and sulphate cause to diminish the uptake of $\mathrm{Cr}(\mathrm{VI})$. These anions may compete with the dichromate ions by hooded firmly on the active sites of the adsorbents. Although, the $\mathrm{pH}_{\mathrm{PZC}}$ of the adsorbents proposes that electrostatic repulsion acts an important role, the 


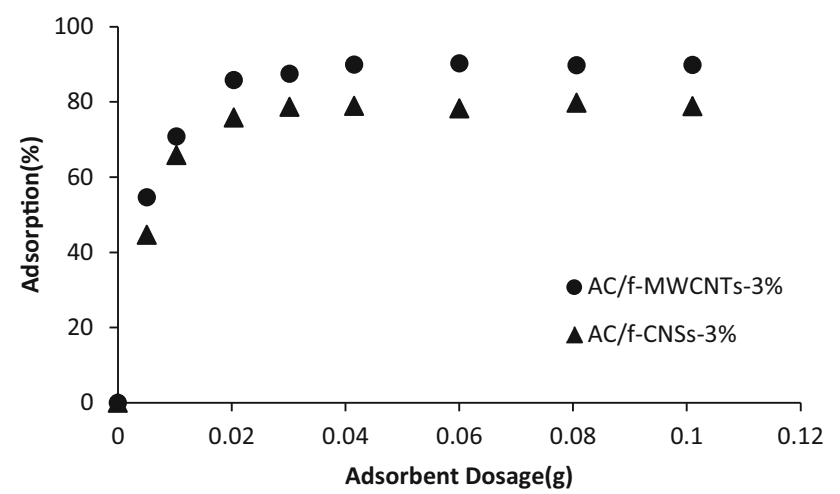

Fig. 6 The effect of amount of adsorbent (adsorbent amount: $0.01-0.1 \mathrm{~g}, \mathrm{pH}=2.2, T=25^{\circ} \mathrm{C}$, conc. $\left.=1 \times 10^{-3} \mathrm{M}\right)$

dichromate ions are larger than the hydroxyl, chloride and sulphate ions and can thus be easily displaced from the adsorption sites of $\mathrm{AC} / f$-MWCNTs and $\mathrm{AC} / f$-CNSs.

\section{Desorption and reusing of AC/f-MWCNTs and $\mathrm{AC} / \mathrm{f}-\mathrm{CNSs}$}

Desorption studies were carried for the all adsorbents for further using it in the adsorption process. Desorption efficiency of $\mathrm{Cr}(\mathrm{VI})$ ions from $\mathrm{AC} / f$-MWCNTs and $\mathrm{AC} / f$ CNSs was studied with $0.1 \mathrm{M} \mathrm{HCl}$ and $0.1 \mathrm{M} \mathrm{NaOH}$. After treatment with acid or bases, the adsorbents could be reused for further adsorption processes since they had not lost their adsorption/desorption abilities that preserved their performance. The $\mathrm{Cr}(\mathrm{VI})$ desorption takes place to a faster extent for the adsorbents at a higher $\mathrm{pH}$ value. The $\mathrm{Cr}(\mathrm{VI})$ desorption occurs at high $\mathrm{pH}$ values due to the fact that the dichromate ions are deprotonated at the same $\mathrm{pH}$ levels and the excess amount of hydroxyl ions compete with them. This suggests that the excess hydroxyl ions present at high $\mathrm{pH}$ values helps in the desorption of $\mathrm{Cr}(\mathrm{VI})$ by repelling the negatively charged dichromate ions [34].

\section{Conclusions}

The investigation based on the adsorption showed that the AC supported with $f$-MWCNTs in tubular form gives higher adsorption capacity compared to the other form of spheres. The highest adsorption capacity using an AC supported with $f$-MWCNTs was $113.29 \mathrm{mg} / \mathrm{g}$. The combination of the AC with $f$-MWCNTs makes adsorption for $\mathrm{Cr}(\mathrm{VI})$ powerful in the synthetic aqueous solution. Langmuir equation was suitable for the equilibrium isotherm data. The main parameters that favour the adsorption of $\mathrm{Cr}(\mathrm{VI})$ onto $\mathrm{AC} / f$-MWCNTs and $\mathrm{AC} / f$-CNSs are time, $\mathrm{pH}$ and initial concentrations of $\mathrm{Cr}(\mathrm{VI})$ and adsorbents could be regenerated and reused well without any appreciable effect on its performance.

$\mathrm{AC} / f$-MWCNTs and AC/f-CNSs are generally considered environmentally friendly materials and do not pose an environmental problem. AC/f-MWCNTs and $\mathrm{AC} / f$-CNSs provide some properties such as good mechanical strength, large internal surface area, large adsorption capacity, easy regeneration and low cost. Hence, they can be employed efficiently to the process that will remove $\mathrm{Cr}(\mathrm{VI})$ from wastewater.

Acknowledgments The authors thank TÜBA (Turkish Academia of Sciences) and Selçuk University, BAP (Project number-14101008) for the financial support.

Open Access This article is distributed under the terms of the Creative Commons Attribution License which permits any use, distribution, and reproduction in any medium, provided the original author(s) and the source are credited.

\section{References}

1. Tour, J.M.: Transition to organic materials science, passive, active and hybrid nanotechnologies. J. Org. Chem. 72, 7477-7496 (2007)

2. Di, Z.C., Ding, J., Peng, X.J., Li, Y.H., Luan, Z.K., Liang, J.: Chromium adsorption by aligned carbon nanotubes supported ceria nanoparticles. Chemosphere 62, 861-865 (2006)

3. Pillay, K., Cukrowska, E.M., Coville, N.J.: Multi-walled carbon nanotubes as adsorbents for the removal of parts per billion levels of hexavalent chromium from aqueous solution. J. Hazard. Mater. 166, 1067-1075 (2009)

4. Rao, G.P., Lu, C., Su, F.: Sorption of divalent metal ions from aqueous solution by carbon nanotubes: a review. Sep. Purif. Technol. 58, 224-231 (2007)

5. Gao, Z., Bandosz, T.J., Zhao, Z., Han, M., Qiu, J.: Investigation of factors affecting adsorption of transition metals on oxidized carbon nanotubes. J. Hazard. Mater. 167, 357-365 (2009)

6. Ahmadpour, A., Eftekhari, N., Ayati, A.: Performance of MWCNTs and a low-cost adsorbent for chromium(VI) ion removal. J Nanostruct. Chem. 4, 171-178 (2014)

7. Stafiej, A., Pyrzynska, K.: Adsorption of heavy metals ions with carbon nanotubes. Sep. Purif. Technol. 58, 49-52 (2007)

8. Allen, S.J., Whitten, L., Mckay, G.: The production and characterization of activated carbons: a review. Dev. Chem. Eng. Min. 6, 231-261 (1998)

9. Yang, R.T.: Adsorbents: Fundamentals and Applications. John Wiley \& Sons, Hoboken (2003)

10. Atieh, M.A.: Removal of chromium (VI) from polluted water using carbon nanotube supported with activated carbon. Procedia Environ. Sci. 4, 281-293 (2011)

11. Adams, R.M.: Occupational Skin Diseases, 2nd edn. W.B. Saunders, Philadelphia (1990)

12. Sheehan, P.J., Meyer, D.M., Sauer, M.M., Paustenbach, D.J.: Assessment of the human health risks posed by exposure to chromium contaminated soil. J. Toxicol. Environ. Health. 12, 161-201 (1991)

13. Youssef, A.M., El-Nabarawy, T., Samra, S.E.: Sorption properties of chemically activated carbons. 1. Sorption of cadmium(II) ions. Colloids Surf. A hysicochem. Eng. 235, 153-163 (2004) 
14. Khezami, L., Capart, R.: Removal of chromium(VI) from aqueous solution by activated carbons: kinetic and equilibrium studies. J. Hazard. Mater. 123, 223-231 (2005)

15. US Environmental Protection Agency (USEPA): Environmental pollution control alternatives: drinking water treatment for small communities. USEPA, Washington, DC (1990)

16. Pandey, S., Mishra, S.B.: Organic-inorganic hybrid of chitosan/ organo clay bionano composites for hexavalent chromium uptake. J. Colloid Inter. Sci. 361, 509-520 (2011)

17. Dakiky, M., Khamis, M., Manassra, A., Mereb, M.: Selective adsorption of chromium(VI) in industrial wastewater using lowcost abundantly available adsorbents. Advan. Environ. Res. 6, 533-540 (2002)

18. Najafpoor, A., Soleimani, G., Ehrampoush, M.H., Ghaneian, M.T., Salmani, E.R., Takabi, M.D.: Study in synthesis and characterization of carbon nanotubes decorated by magnetic iron oxide nanoparticles. Int. Nano. Lett. 4(4), 129-135 (2014). doi: 10.1007/s40089-014-0128-1

19. Gadhave, A., Waghmare, J.: Removal of heavy metal ions from wastewater by carbon nanotubes (cnts). Int. J. Chem. Sci. Appl. 5, 56-67 (2014)

20. Wepasnick, K.A., Smith, B.A., Schrote, K.E., Wilson, H.K., Diegelmann, S.T., Fairbrother, D.H.: Surface and structural characterization of multi-walled carbon nanotubes following different oxidative treatments. Carbon 49, 24-36 (2011)

21. Zhang, S., Zeng, M., Xu, W., Li, J., Li, J., Xu, J., Wang, X.: Polyaniline nanorods dotted on graphene oxide nanosheets as a novel super adsorbent for $\mathrm{Cr}(\mathrm{VI})$. Dalton Trans. 42, 7854-7858 (2013)

22. Hua, J., Chena, C., Zhub, X., Wanga, X.: Removal of chromium from aqueous solution by using oxidized multiwalled carbon nanotubes. J. Hazard. Mater. 162, 1542-1550 (2009)

23. Nassereldeen, A., Muataz, A.A., Abdullah, A., Mohamed, E.S., Alam, M.D., Yahya, N.: Kinetic adsorption of application of carbon nanotubes for $\mathrm{Pb}(\mathrm{II})$ removal from aqueous solution. J. Environ. Sci. 21, 539-544 (2009)

24. Muataz, A.A., Fettouhi, M., Al-Mammum, A., Yahya, N.: Lead removal by using carbon nanotubes. Int. J. Nanoparticle 2, 329-338 (2009)
25. Nxumalo, E.N.: Synthesis of monofunctionalised cyclodextrin polymers for the removal of organic pollutants from water. M.Sc. Thesis, University of Johannesburg (2006)

26. Kandah, M.I., Meunier, J.L.: Removal of nickel ions from water by multiwalled carbon nanotubes. J. Hazard. Mater. 146, 283-288 (2007)

27. Ahmadpour, A., Eftekhari, N., Ayati, A.: Performance of MWCNTs and a low-cost adsorbent for Chromium(VI) ion removal. J. Nanostructure Chem. 4, 171-178 (2014)

28. Mor, S., Ravindra, K., Bishnoi, N.R.: Adsorption of chromium from aqueous solution by activated alumina and activated charcoal. Biores. Technol. 98, 954-957 (2007)

29. Li, Y., Gao, B., Wu, T., Sun, D., Li, X., Wang, B., Lu, F.: Hexavalent chromium removal from aqueous solution by adsorption on aluminium magnesium mixed hydroxide. Water Res. 43, 3067-3075 (2009)

30. Kyzas, G.Z., Kostoglou, M., Lazaridis, N.K.: Copper and chromium(VI) removal by chitosan derivatives-equilibrium and kinetic studies. Chem. Eng. J. 152, 440-448 (2009)

31. Liu, M., Wen, T., Wu, X., Chen, C., Hu, J., Lia, J., Wanga, X.: Synthesis of porous $\mathrm{Fe} 3 \mathrm{O} 4$ hollow microspheres/graphene oxide composite for $\mathrm{Cr}(\mathrm{VI})$ removal. Dalton Trans. 42, 14710-14717 (2013)

32. Pehlivan, E., Tran, H.T., Ouédraogo, W.I.K., Schmidt, C., Zachmann, D., Bahadir, M.: Removal of As(V) from aqueous solutions by iron coated rice husk. Fuel Process. Tech. 106, 511-517 (2013)

33. Pehlivan, E., Kahraman, H., Pehlivan, E.: Sorption equilibrium of $\mathrm{Cr}(\mathrm{VI})$ ions on oak wood charcoal (Carbo Ligni) and charcoal ash as low-cost adsorbents. Fuel Process. Tech. 92, 65-70 (2011)

34. Mungasavalli, D.P., Viraragavhan, T., Jin, Y.C.: Biosorption of chromium from aqueous solution on Aspergillus niger: batch and column studies. Colloids Surf. A Physicochem. Eng. Asp. 301, 214-223 (2007) 